\title{
DIGITAL TRANSFORMATION AT HIGH EDUCATION: ARE PROFESSORS OF THE SOUTH EUROPEAN AND SOUTH AMERICAN COUNTRIES PREPARED FOR THAT?
}

\author{
Maria João Ferreira ${ }^{1,4}$, Carla Santos Pereira ${ }^{1,5}$, Fernando Moreira ${ }^{1,2,3}$, Natércia \\ Durão1 \\ ${ }^{1}$ Univ Portucalense, Research on Economics, Management and Information Technologies - \\ REMIT (PORTUGAL) \\ ${ }^{2}$ Univ Portucalense, Portucalense Institute for Legal Research - IJP (PORTUGAL) \\ ${ }^{3}$ IEETA, Universidade de Aveiro (PORTUGAL) \\ ${ }^{4}$ Centro Algoritmi, Universidade do Minho (PORTUGAL) \\ ${ }^{5}$ CEMAT, Instituto Superior Técnico, Universidade Técnica de Lisboa (PORTUGAL)
}

\begin{abstract}
The higher education plays a fundamental role in the society transformation in all of its dimensions, namely teaching, educational management, vision and creation of business and professions. The combination of new challenges in higher education with the increase of mobile technologies (one of the digital transformation pillars) leads to an intensification in teaching opportunities and demands of new teaching methods development. Due to this, several concepts from the e_learning, to u_learning appeared. Therefore, it is critical to understand whether users (students and professors) are receptive and aware to adapt to this new paradigm before deciding to implement teaching-learning methods based on mobile technology. In this context, the aim of the study presented is to investigate if higher education professors, in the technology area, in South Europe and South America countries, are using Mobile Learning with gamification and augmented reality apps and how they can be used to promote student's engagement inside and outside of the classroom, in order to prepare the students for a new reality - the digital transformation.
\end{abstract}

Keywords: Mobile learning, Professors, Mobile devices, Higher Education Institutions, South Europe, South American countries, Gamification, Augmented Reality.

\section{INTRODUCTION}

The higher education plays a fundamental role in the society transformation in all of its dimensions, namely teaching, educational management, vision and creation of business and professions. The expected evolution/transformation in terms of the potential introduced by the adoption of technology and virtual approaches to the teaching-learning process (TLP) [1], mobile learning (m_learning) [2] and ubiquitous learning (u_learning) [3], are still in an embryonic state. Since, these approaches are used, but professors do not sufficiently exploit their potential and the objectives for which they were proposed.

The massive use of mobile devices (MD) associated with other technologies (cloud computing, big data and social media), allows educational institutions to go beyond incrementing and updating the TLP, enabling a deeper knowledge of the stakeholders (students, professors and other elements), and in this way to predict difficulties in several intervention levels (educational, management, etc.) in institutions. In this context, the technologies presented above, pillars of Digital Transformation (DT) [4], are driving organizations, including high education institutions (HEI), to the next level of digital customer engagement and IT-enabled business processes, products, and services.

Educational systems in developed countries have promoted strong policies and strategies to address the educational needs of the 21st century. However, these needs are difficult to implement/operationalize, namely with regard to new teaching methods in HEls such as active methodologies that to meet the type of students which are coming to the higher education level [5].

As $M D$ and ubiquitous computing technologies create a unique learning opportunities, $m$ learning is increasingly seen as an advantage for TLP in HEls [6], since its characteristics meet the characteristics of these students, named Generation Z. Fundamentally, m_learning is based on the use of MD anywhere at any time and the prevalent use of portable technologies facilitates the TLP 
when and where students intend to access learning materials. Furthermore, the capabilities of MD have led to the emergence of technologies that have opened up new possibilities in the TLPs, namely Augmented Reality (AR) and Gamification (G).

As a result, the successful integration of $m_{-}$learning technologies in education require the perception of these technologies by professors, and it is possible to formulate the research question "How do professors percept the importance of m_learning in DT?". In this context, the aim of the study presented is to investigate if professors, in South Europe (SE) and South America (SA), are using $m$ learning with $A R$ and $G$ apps, and how they can be used to promote student's engagement inside and outside of the classroom, in particular to prepare the students for DT. To this end, the research carried out used the quantitative methodology.

The paper is structured as follows. Section 2 critically examines m-learning and DT concepts, and the relationship between them. Section 3 presents the state of the art of m-learning in the perspective of $\mathrm{HEI}$. Section 4 presents the research methodology. Section 5 summarizes the results and discussion of the research and finally, and section 6 presents the study conclusions.

\section{BACKGROUND}

\section{1 m_learning}

Mobile learning ( $m$ learning) can be considered as the natural evolution of e-learning the predecessor of u_learning [3]. This concept will allow any student of any age, from any school level, to study and access learning materials anytime, anywhere.

Moreira, et al. [2] present a study on m_learning in which are summarized the definitions of $\mathrm{m}$ learning presented in the literature. The latter definition dates from 2017 and extends the scope of other definitions by considering m_learning as "the learning strategy that provides students with the 21 st century learning capabilities in order to enable them to use the wide range of the portable computing devices" [7]. This definition addresses, on the one hand, the training needs of students who arrive to higher education, and on the other hand the skills considered fundamental that students acquire [8].

M_learning is not a one-dimensional approximation and therefore must be observed/analyzed in all its dimensions; according to Al-Emran and Shaalan [9] m_learning has three dimensions: (1) technology mobility (hardware and software, in special augmented and virtual reality, with possibilities to be adapted for educational purposes to stimulate learning within and outside the classroom [10], (2) student and teacher mobility (this is related to the fact that today everyone has one or more mobile devices and is connected to the Internet) and (3) learning mobility / educational context (according to [11] it is necessary to integrate tools, pedagogical approaches, assessment techniques and teacher training).

The literature shows that $m$ learning contains itself several benefits, from both point of view educational and technological. According to Miangh and Nezarat [12] the learning process can be personalized, omnipresent, spontaneous and informal, as well as practical and inexpensive. Valero et al. [13] point to the benefits of portability, immediacy, connectivity, ubiquity and adaptability. Allowing for greater collaboration among students, creation of knowledge and skills, and better interaction and communication between teacher and student [14]. Despite the advantages identified in the literature and presented here, however, there are always contrasting scenarios in all contexts, including m_learning [15], such as student performance, known to be "effective", can be disappointing or can even adversely affect students if they do not have a proper treatment Chu [16].

\subsection{Digital transformation}

The definition of digital transformation (DT) is not consensual among the stakeholders involved in this issue, particularly in organizations, leading to several perspectives of what it really means. According to Solis [17] DT may be defined as "the realignment of, or new investment in, technology, business models, and processes to drive new value for customers and employees and more effectively compete in an ever-changing digital economy". 
Following this line of reasoning, from the organizations point of view, DT can be seen as a deep and accelerating transformation with regard to processes, activities, competences and models, in order to take advantage of the changes and opportunities offered by the inclusion of digital technologies into an organization. On the other hand, Uhl and Gollenia [4] enrich the DT concept, arguing that the adoption of technology-based change is focused on four technology enablers: (1) cloud computing, (2) mobile, (3) social, and (4) big data - analytics.

The results of introducing, among others, social media tools in business and education system were very positive and resulted in the revitalization of many businesses and reference companies in their areas of intervention. However, the rapid evolution of technology has led to the emergence of new solutions that led to the emergence of the so called 3rd technology platform (early 2010), which is based, as previously described in four technology enablers or pillars. The more significant use of the pillars of digital transformation has been driven by innovation accelerators, which include, among other solutions, IoT, Robotics, 3D Printing, Artificial Intelligence, Augmented and Virtual Reality, Cognitive Systems and Next Generation (NextGen) Security (Figure 1). To this extent, IDC expects that in, $2019,3^{\text {rd }}$ platform technologies and services will account for about $75 \%$ of IT spending by the organizations [18].

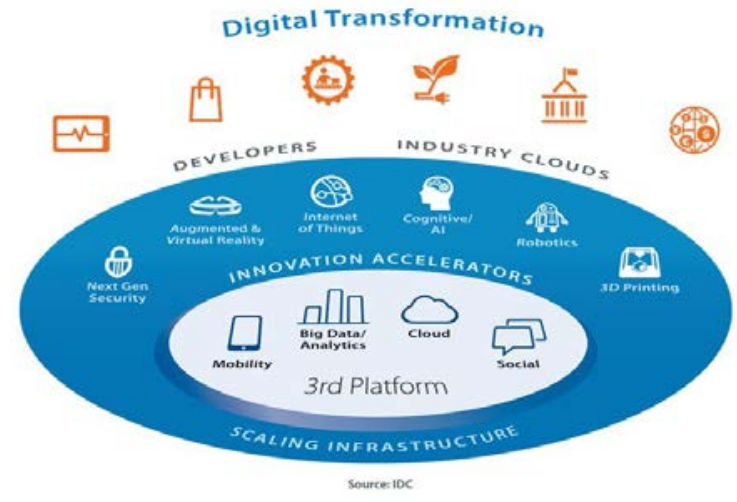

Figure 1. Digital transformation - Pillars and innovation accelerators (adapted from [18]).

One of the main advantages of digital transformation is the possibility of expanding physical to digital business. For example, one of the innovation accelerators, virtual reality technology, can be applied to the real estate market to conduct visits to fully digital properties, whereas in the medical field, the same resource can be applied to offer virtual training of surgeries and study of organisms.

\section{STATE OF THE ART}

The literature in the field of m_learning is vast. However, studies that highlight the position of professors in South European and South American countries, related with m_learning approaches, with gamification and augmented reality are non-existent. Only the study presented in [19] this topic is investigated and analyzed, but in Portugal. In that study authors concluded that most Portuguese professors have knowledge on how to perform the most trivial tasks with mobile devices and shown high results on the utilization of both $A R$ and gamification applications.

For the construction of the state of the art, the B-on portal (www.b-on.pt) was used. B-on is an Online Library of Knowledge that provides unlimited and permanent access to thousands of international scientific journals and e-books. The number of papers on the applicability of m_learning from the professors' point of view is reduced globally, and it was verified that papers presenting studies relating to HEls in South Europe and South American countries were non-existent. The research was carried out for the period 2014-2017 with the following queries search: (1) "(mobile learning OR m_learning OR mLearning OR Mobile Learning) AND (South American countries) AND (South European countries) AND (Augmented reality) AND (Gamification)"; (2) "(mobile learning OR m_learning OR mLearning OR Mobile Learning) AND (South American countries) AND (South European countries)"; (3) "(South American countries) AND (South European countries) AND (Augmented reality) AND (Gamification)" it was the inexistence of any paper related with these issues. To verify that there are already studies performed when the search is "(mobile learning OR m_learning OR mLearning OR Mobile Learning) AND (Augmented reality) AND (Gamification)", there were 509 entries, even though most of them are not directly related to the entire search query. In this context, from this study it was 
possible to conclude that there is none comparative studies on mobile technologies in education, particularly between HEls from South American and South European countries, thus making the research relevant and justified.

\section{RESEARCH METHODOLOGY}

In the field of research the main element is the use of a scientific method, in order to carry out an organized research, to have a strict control of the use of theoretical observations and knowledge. Thus, this section presents the procedures used in data collection; which constitute the basis of the research / study presented.

The research carried out used the quantitative methodology, which can be generically defined as a method of social research that uses statistical techniques for the collection and analysis of data. The quantitative methodology is thus, with the collection of data on motivations of concrete groups, in the understanding and interpretation of certain behaviors, opinions and expectations of a concrete group of individuals. This approach aims essentially to find relationships between variables, to make descriptions using the statistical treatment of collected data, to test theories and to draw conclusions [20]. The selection of the quantitative methodology is justified by the need to collect the opinions and attitudes of the respondents, i.e. the study was descriptive in nature, and the data collection was carried out with the use of a questionnaire.

The use of questionnaires requires special care, since it is not enough to collect the answers on the issues of interest, it is also important to perform a statistical analysis for the validation of the results. Aspects such as sample size, questionnaire formulation, data analysis, among others, are important and should be taken into account in research [21]. The questionnaire before being submitted was submitted to the evaluation of four experts in the area.

The aim of this study is to investigate if higher education professors in the area of technology, in South Europe (SE) and South America (SA), prepare their students for digital transformation (by using mobile technologies, such as, for example gamification and augmented reality apps). The quantitative study was based on an online questionnaire with 41 questions (Q1-Q41) relating to 6 sections (Demographic information, Prior knowledge, Participation/Engagement, Use of Mobile Devices (MD), Mobile use in the classroom and Self-efficacy). The first section consists of 6 questions, which include, for example, the age and gender. The second section consists of a question (Q7) with 11 items about professor's knowledge concerning MD (in particular, the items 10 and 11, with regard to whether they know how to download augmented reality and gamification apps on a MD). The third section contains 18 questions, 15 of which relate to professor's opinions about students Participation/Engagement (inside and outside) class activity if they use their MD and 3 questions about the incorporation of MD, augmented reality and gamification in classes. The fourth section concerns a question with 15 items about how to use MD to perform educational tasks inside or outside the classroom (in particular the last 2 items regarding if students play an educational game on their MD or use their MD with augmented reality as a learning tool). In fifth section, we have 12 questions (Q27-Q38) about the use of the MD in the classroom (that is, what professors think about incorporating mobile learning in their classes and the ability of students to use them appropriately), two of these questions specifically refer to whether professors believe that students can be taught how to use MD with augmented reality apps and with gamification apps for learning. Finally, in the last section we have 3 questions (Q39-Q41) about self-efficacy. Almost all questions were close-ended type (Q38 and Q40 are the exceptions). Sections 2 and 4 use nominal scale (Yes (1)/ No (0)). Section 3 use five-point Likert scale ranging from "Strongly Disagree" (1) "Disagree" (2), "Neutral" (3), "Agree" (4) and "Strongly Agree" (5) and section 5 in the first 10 questions (Q27-Q36). Additionally, in question Q37 of section 5 we use a nominal scale (incorporate MD/ incorporate MD with training/ not incorporate).

The questionnaire has been online for 60 days and 141 valid responses were received. Data collected were treated by using the IBM SPSS Statistics 24.0 software. Statistical analyses used in our study were Descriptive Analysis (frequency analysis, descriptive measures and graphical representations) and Inferential Analysis: non-parametric (MANOVA one-way, Chi-square test, Mann-Whitney test and Kruskal-Wallis test), correlation analysis and reliability analysis (Cronbach's Alpha). 


\section{ANALYSIS AND RESULTS DISCUSSION}

The study sample consists of 141 professors (61 from South America (SA) and 80 from South Europe (SE)) from the area of technology in HEls. Most professor's gender were male $(68.8 \%$ from SE and $60.7 \%$ from SA) whereby, the majority of professors in SE were aged between 41 to 50 years old $(52,5 \%)$, for SA professor's the majority were between 31 to 50 years old $(65,6 \%)$.

Considering that professors can simultaneously teach various levels of teaching degrees, we find interesting to analyze the level of education they teach by continent. We can conclude that SE professors teach in a higher proportion in $\mathrm{PhD}$ and Master's degree $(48.8 \% / 65.0 \%$, respectively), than the SA $(36.1 \% / 39.3 \%$, respectively). In relation to the Degree, the proportion is identical for the professors of both continents (above 70\%). More, we found that in SA most of them (approximately $62 \%)$ teach only one level and in SE, professors teach more frequently one or three degrees $(40 \%$ and $35 \%$, respectively). This may be due to the oldest age of SE professors.

We performed a reliability analysis using Cronbach's Alpha (this measure varies between 0 and 1 and higher values are the more desirable) to verify if the variability of the answers resulted from differences in professor's opinions.

Cronbach's Alpha for the four dimensions (corresponding to sections 2 to 5), which are "Prior Knowledge" (Dimension 1), "Participation/Engagement" (Dimension 2), "Use of Mobile Devices" (Dimension 3) and "Mobile use in the classroom" (Dimension 4) are presented in Table 1.

Table 1. Cronbach's Alpha coefficients.

\begin{tabular}{l|c|c}
\hline \multicolumn{1}{c|}{ Dimension } & Cronbach's Alpha & $\mathrm{N}^{\circ}$ of Items \\
\hline 1. Prior Knowledge & 0.851 & 11 \\
\hline 2. Participation / Engagement & 0.930 & 18 \\
\hline 3. Use of mobile devices & 0.862 & 15 \\
\hline 4. Mobile use in the classroom & 0.922 & 10 \\
\hline
\end{tabular}

For Dimensions 1 and 3 we can observe that Cronbach's Alpha coefficients lies between 0,8 and 0,9 which can be considered good. For Dimensions 2 and 4 the values are excellent because they exceed 0,9 [22]. Moreover, we evaluated the internal consistency separated by continent and we obtained identical conclusions.

Because all dimensions are considered reliable, it makes sense to calculate descriptive measures (percentages, mean and standard deviation, according to measurement scale) for each item/question. Some results of the analysis can be found, resumed, in Table 2 (Dimension3), Figure 2 (Dimension 2) and Figure 3 (Dimension 4).

Concerning "Prior Knowledge" (Dimension 1), the results of the percentages of Yes responses of the 11 items, by continent show that, for items 1 to 9 , that the majority of these professors have excellent knowledge (with percentages at least $85 \%$ ) on how to perform the most trivial tasks (such as, "Connect and access internet", "Send and receive emails/text messages", etc....). The only exception is "Access college resources such as LMS, payroll, etc., on a MD" (about $70 \%$ ). Despite being new technologies for digital transformation, we denoted that although still high $(>50 \%)$, we found a decrease when the prior knowledge is related to download Augmented Reality applications and Mobile App Gamification on a MD (items 10 and 11), for professors of both continents. However, to confirm this perception obtained by exploratory analysis, we used independence Chi-square test (inferential statistical analysis) and obtained $p$-value $=0,272$ and $p$-value $=0,406$ for item 10 and 11 , respectively. So, professor's opinions is independent of the continent to which they belong.

Given these results, as in (Moreira et al., 2018), it seemed of interest to verify, for each continent, if the gender of the professors is independent of their knowledge on how to download Augmented Reality and Gamification apps on a MD. All conditions of applicability of Chi-Square test with continuity correction were checked [22][23]. 
For item 10 we found a p-value of 0,023 for SE and 0,010 for SA (smaller than 0,05 ) so we can conclude that gender has influence in prior knowledge for both continents. Analyzing in detail the contingency tables constructed for the Chi-square test, we found that for female "No" predominates $(54,2 \% / 66,7 \%$ for SE and SA respectively) and for males the "Yes" predominates (75\% / 70,3\% for SE and SA respectively).

With regard to item 11, in SE the gender does not influence in prior knowledge ( $p$-value $=0,801>$ 0,05 ) because, whatever the gender, "Yes" predominates. For the SA professors, there is a similar behavior to that of item 10 .

In terms of "Participation/Engagement" (Dimension 2) the overall mean value and variation coefficient (\%), for each continent, 3,93 / 15,8\% for SE and 4,17 / 16,8\% for SA, is close to the value 4 (agree position), which suggested that professors think that students will have greater involvement and participation in activities if they use their MD and these opinions are also consistent (variation coefficient $<20 \%$ ). As can be seen in Figure 2, these values seem higher in SA.

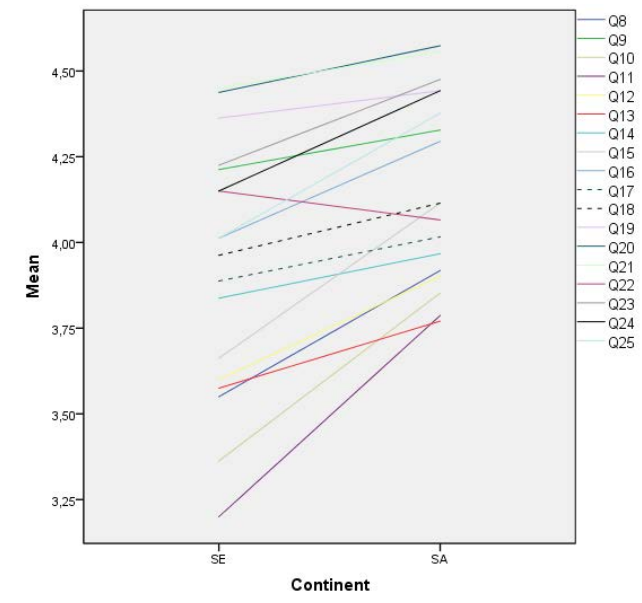

Figure 2. Behaviour of the mean of "Participation/Engagement" in both continents.

Summarizing, the opinion of professors of SA is always more positive except for question Q22 ("Students should be able to take quizzes on their MD") as is clearly visible in Figure 2. Focusing again this study on the new technologies for digital transformation, we opt by non-parametric tests (the hypothesis of Normal distribution was not verified) and perform the Mann-Whitney statistical test, adequate for variables measured in a ordinal scale, in order to assess whether there are differences in professors opinions, to incorporate into classrooms, Augmented Reality (Q17), and gamification (Q18) according continent ( $p$-value $=0,486$ and $p$-value $=0,345$, for $S E$ and $S A$, respectively). These results lead us to conclude that, although the values seem higher in SA, there is no statistically significant differences in regard of the continent. Note that, Q17 and Q18 are represented with a broken line in Figure 2.

In regard to "Use of MD" (Dimension 3), in the sense, of what educational tasks professors ask students to do (inside or outside the classroom), opinions about the use of MD's are identical (Table 2 ) in both continents with exception of item 3 ("Engage in social networking on their MD"). For this item there is a reversal in the opinion between SE professors and SA professors, that is, whereas for SE professors, "No" is predominant (60\%), for SA professors no. Perhaps SE professors do not view social networks as a suitable study tool in the context of digital transformation. It is interesting to note that all items that refer to "Text a classmate..." (Items 6 to 9) and "Use their MD with augmented reality as a learning tool" (item 15) predominate the "No" response in both continents, maybe, for the professors, in the classroom fact that disturbs the proper functioning of the classes. As for Dimensions 1 and 2, from the point of view of digital transformation, it should also be noted that in relation to "Play an educational game on their MD" (item 14), the "Yes" predominates although with a significantly lower percentage than in the other items. To compare the opinions about items 14 and 15, in both continents, from the inferential point of view, we used independence Chi-square test that provides $p$ value $=0,581$ and $p$-value $=1,000$ for items 14 and 15 , respectively, which means that professor's opinions is independent of the continent to which they belong. 
Table 2. Percentages of Yes responses of the 15 items of "Use of MD" (Q26) by continent.

\begin{tabular}{l|c}
\hline \hline I would ask students to... & $(\mathrm{SE} / \mathrm{SA})(\%)$ \\
\hline 1. Download applications that help them learn new subjects & $68,8 \% / 77 \%$ \\
\hline 2. Use MD to look up something that they didn't know or understanding during class & $70,0 \% / 67,2 \%$ \\
\hline 3. Engage in social networking on their MD & $\mathbf{4 0 , 0 \% / 5 2 , 5 \%}$ \\
\hline 4. Write notes on their MD to remind themselves of an assignment & $67,5 \% / 63,9 \%$ \\
\hline 5. Set alarms or reminders on their MD to help them remember an & $65,0 \% / 63,9 \%$ \\
\hline 6. Text a classmate during class & $21,3 \% / 34,4 \%$ \\
\hline 7. Text a classmate about the contents of the class & $40,0 \% / 42,6 \%$ \\
\hline 8. Text a classmate about the professor's ability & $17,5 \% / 24,6 \%$ \\
\hline 9. Text a classmate about the level of engagement in the class & $18,8 \% / 29,5 \%$ \\
\hline 10. Take a picture or video with their MD that they could be used for an assignment & $65,0 \% / 67,2 \%$ \\
\hline 11. Access an LMS (e.g. Moodle) on their MD & $\mathbf{7 7 , 5 \% / 8 3 , 6 \%}$ \\
\hline 12. Read a paper or assignment on their MD & $62,5 \% / 72,1 \%$ \\
\hline 13. Use their MD as a study tool & $60,8 \% / 70,5 \%$ \\
\hline 14. Play an educational game on their MD & $\mathbf{5 1 , 3 \% / 5 7 , 4 \%}$ \\
\hline 15. Use their MD with augmented reality as a learning tool & $\mathbf{4 8 , 8 \% / 4 7 , 5 \%}$ \\
\hline \hline
\end{tabular}

For "Mobile use in the classroom" (Dimension 4) the overall mean and variation coefficient (\%) for the 10 questions, for each continent, are $3,85 / 19 \%$ for SE and $4,24 / 19,6 \%$ for SA. The mean is close to the value 4 (agree position) and opinions are consistent for professors in both continents (variation coefficient $<20 \%$ ). As can be seen in Figure 3, these values seem higher in SA and suggest that professors of both continents agree about students using MD in classroom.

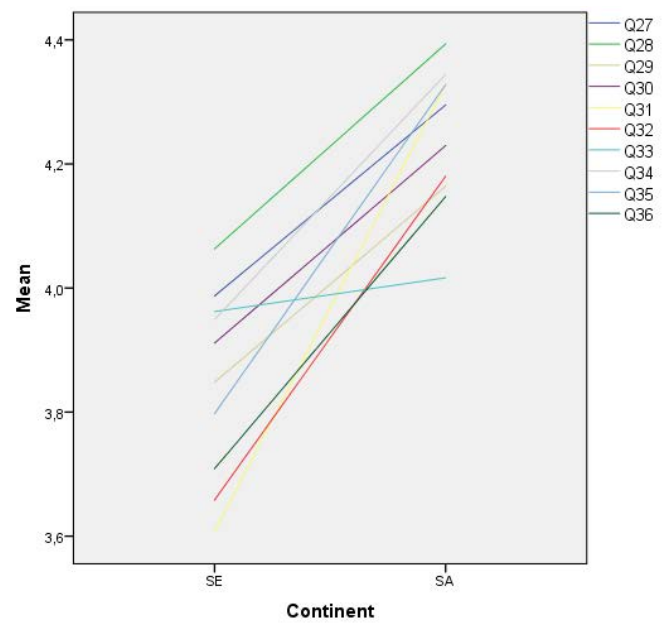

Figure 3. Behaviour of the mean of "Mobile use in the classroom" in both continents.

In order to evaluate whether continent influence the professor's opinions regarding all questions given the measurement scales of the variables are ordinal, we performed a Mann-Whitney statistical test. Since all p-values are smaller than 0,05, with exception to question Q33 ("Students would think is fun to use an interactive $M D$ in my classroom") with $p$-value=0,445, we can conclude that there are statistical significant differences between the opinions about students using MD in classroom for learning in the sense that in SA professors have a upper tendency to believe that students can appropriately use MD in the classroom. In this dimension, the results are in line with what we have already seen above. 
Concerning "Incorporation of mobile learning in the classroom" (Q37), we found that the majority $(62,3 \%)$ of SA professors said will be able to effectively incorporate this with training against $45 \%$ of SE professors. It should also be noted that the low percentage of professors from both continents $(11,3 \%$ in $S E$ and $4,9 \%$ in $S A)$ not think will be able to effectively incorporate mobile learning.

In order to evaluate globally the professors' opinions about "Participation / Engagement" (Dimension 2) and "Mobile use in the classroom" (Dimension 4), we constructed two indices (mean_D2 and mean_D4) that represent the arithmetic mean of variables that integrate each dimension.

To identify if there was a relationship between the indices "mean_D2" and "mean_D4" by continent, we calculate Pearson correlation coefficient. Correlation analysis confirms the significant positive relationship ( $r=0,848$ in $\mathrm{SE}$ and $r=0,884$ in $\mathrm{SA})$ at the 0,01 level. That is, whatever the continent, the professors that most agree in Dimension 2 (Participation/Engagement) are those who most agree in Dimension 4 (Mobile use in the classroom).

To verify if we can perform tests of parametric hypotheses, we start by evaluating whether the two variables (indices "mean_D2" and "mean_D4") follow a Normal distribution (Kolmogorov-Smirnov test with Lilliefors correction). This hypothesis was not verified for these variables in the SA continent. At the same time we proceeded to the M-Box test for the homogeneity of covariance matrices that provided a p-value of $0.719>0.05$. As the assumption of normality does not occur, we will choose to use non-parametric alternatives (MANOVA one-way) to know if the continent (factor) to which the professor belongs influences his opinion about the two variables above. As the nonparametric methods for multivariate designs are based on the orders of the observations we have to work with "rank_mean_D2" and "rank_mean_D4" (as there were ties, to these cases was attributed the average of the orders they would have if they were not tied). We can proceed to the analysis of the results of the Multivariate tests (Table 3).

Table 3. Multivariate tests (factor-continent, dependent variables-rank_mean_D2 e rank_mean_D4).

\begin{tabular}{|c|l|r|r|r|r|c|}
\hline \multicolumn{1}{|c|}{ Effect } & \multicolumn{1}{|c|}{ Value } & \multicolumn{1}{c|}{ F } & Hypothesis df & Error df & Sig. \\
\hline \multirow{3}{*}{ Intercept } & Pillai's Trace &, 791 & 258,982 & 2,000 & 137,000 &, 000 \\
\cline { 2 - 7 } & Wilks' Lambda &, 209 & 258,982 & 2,000 & 137,000 &, 000 \\
\cline { 2 - 7 } & Hotelling's Trace & 3,781 & 258,982 & 2,000 & 137,000 &, 000 \\
\cline { 2 - 7 } & Roy's Largest Root & 3,781 & 258,982 & 2,000 & 137,000 &, 000 \\
\hline \multirow{3}{*}{ Continent } & Pillai's Trace (PT) &, 109 & 8,355 & 2,000 & 137,000 &, 000 \\
\cline { 2 - 7 } & Wilks' Lambda &, 891 & 8,355 & 2,000 & 137,000 &, 000 \\
\cline { 2 - 7 } & Hotelling's Trace &, 122 & 8,355 & 2,000 & 137,000 &, 000 \\
\cline { 2 - 7 } & Roy's Largest Root &, 122 & 8,355 & 2,000 & 137,000 &, 000 \\
\hline \hline
\end{tabular}

The most robust adequate statistic is based on the Pillai Trace (PT), calculated from the orders (rank_mean_D2 and rank_mean_D4) and follows a Chi-Square distribution with 2 degrees of freedom. So, $\bar{\chi}_{\text {obs }}^{2}=(\mathrm{N}-1) \mathrm{PT}=140^{*} 0,109=15,26$. As $p$-value $\approx 0<\alpha=0,05$ we reject the hypothesis that the continent has no influence on the professor's opinion in Dimension 2 and Dimension 4.

In order to identify in which of the two dimensions (mean_D2 and mean_D4) we observe the significant differences, we use the Kruskal-Wallis test for each of the dimensions. For mean_D2 we obtained $p$-value $=0,003$ and for mean_D4 $p$-value $=0,000$. So, as $p$-value $<0,05$ (for both variables), we can conclude that the differences between the continents occur in the two dimensions.

To analyze these differences in more detail, we construct boxplot clusters (Figure 4). We can conclude that there are more SA professors who think that students will have a higher involvement and participation in the activities (mean_D2) if they use their MD, compared to the number of SE professors. Relatively to "Mobile use in the classroom" (mean_D4) this opinion is more evident. Moreover, for both continents, opinions of professors relatively to Participation/Engagement (mean_D2) are more consistent (less dispersion) than relatively to mobile use in the classroom (mean_D4). Also noteworthy is the existence of some moderate (in SE and SA continents) and severe (in SA continent) outliers. Curious that, in general, the opinion of the SA professors has proved more positive, but among those who disagree, their opinion is very unfavorable (outliers referenced as 86 
and 119) corresponding to two professors from the same country, same age group and the same gender).

Regarding the open questions, "How would you like to see mobile devices (mobile learning) incorporated at the college for classwork and administrative functions?" (Q38) and "What are the most important elements (technical and pedagogical) needed for mobile learning to be used in your classroom?" (Q40), stands out the following comments: (i) For the first question: while some professors do not think it's a good idea to incorporate the MD for classwork, most are favourable. That is, some refer that they would like to see them incorporated as complementary practices / support to face-to-face classes (in order to be a learning opportunity for the students to choose), other professors prefer the fully incorporated system and others, even advocate the integration of MDs into the university's e-learning system. (ii) For the second question: a significant number of professors emphasize the need for change of teaching / learning paradigm and teacher training. In relation to the most important elements reference is made to the tablets, laptops, smartphones with android, and iOS, and essentially good and speed Wi-Fi connection. Also, many professors refer the need to have a lot of free and commercial apps available and pedagogical supported and quizzes and forums for fast feedback.

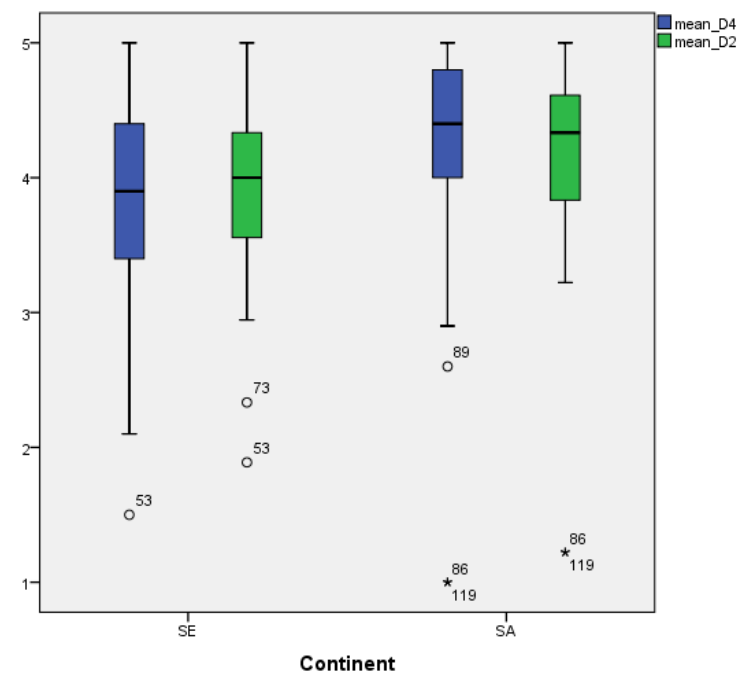

Figure 4. Distribution of mean_D2 and mean_D4 for each continent.

\section{CONCLUSIONS}

In this study we analyzing the use of $m$ _learning with gamification and AR in TLP in high education of the South Europe and South American countries and how professors can promote student's engagement inside and outside of the classroom, in particular to prepare the students for Digital Transformation. From the obtained results, it is possible to conclude that in respect to prior knowledge, the majority of the professors have excellent knowledge on how to perform the most trivial tasks but professor's opinion is independent of the continent to which they belong. Regarding gender, we have found differences in knowledge about how to download augmented reality applications for both continents (with predominance of "No" for female).

In terms of "Participation/Engagement" professors think that students will have greater involvement and participation in activities if they use their MD whatever the continent. In regard to the use of MD, opinions are identical with exception of SE professors that do not view social networks as a suitable study tool (item 3). That are statistical differences between the opinions about students using MD in classroom for learning in the sense that SA professors have a more positive opinion. In this dimension, concerning to the incorporation of mobile learning in classroom, the results reveal the commitment and involvement of SA professors in applying mobile technologies (one of the pillars of digital transformation).

Whatever the continent we concluded that professors that most agree in "Participation/Engagement" are those who most agree in terms of "Mobile use in the classroom". Also, continent as influence on professor's opinions in this dimension in the sense that are more SA professors who think that 
students will have greater involvement and participation in the activities if their use their MD. This opinion is even more evident relatively to "Mobile use in the classroom".

As a final conclusion that can be highlighted that in both continents the behaviors are quite identical in the receptivity of the use of MD to increase the commitment of the students in activities inside and outside the classroom. Nevertheless, it should be noted that SA professors have less prior knowledge about download AR and apps and Mobile app gamification on a MD (especially SA professors).

In relation to Participation / Engagement (Dimension 2), Mobile Use (Dimension 3) of MD and Mobile use in the classroom (Dimension 4) SA's opinions seem more favorable (SA professors more optimist?). However relatively to first two dimensions (Dimension 2 and 3 ) we cannot affirm that there are significant differences.

\section{REFERENCES}

[1] J. Gómez, J. F. Huete, O. Hoyos, L. Perez, D. Grigori, "Interaction System based on Internet of Things as Support for Education," Procedia Comput. Sci., vol. 21, pp. 132-139, 2013.

[2] F. Moreira, M. J. Ferreira, "Teaching and learning modelling and specification based on mobile devices and cloud: A case study," Int. J. Technol. Hum. Interact., Vol. 13., 2017

[3] G. M. Ramirez, C. A. Collazos, F. Moreira, "A systematic mapping review of all-learning model of integration of educational methodologies in the ICT," Advances in Intelligent Systems and Computing, 2017, doi:10.1007/978-3-319-56541-5_35

[4] A. Uhl, L. A. Gollenia, "Digital enterprise transformation: A business-driven approach to leveraging innovative IT," Routledge, 2016.

[5] UNESCO, "Educação: Um tesouro a descobrir. Relatório para a UNESCO da Comissão Internacional sobre Educação para o século XXI," 2000.

[6] F. Moreira, M. J. Ferreira, C. P. Santos, N. Durão, "Evolution and use of mobile devices in higher education: A case study in Portuguese Higher Education Institutions between 2009/2010 and 2014/2015," Telematics and Informatics, vol. 34, pp. 838-852, 2017

[7] A. Al-Hunaiyyan, S. Al-Sharhan, "A New Mobile Learning Model in the Context of the Smart Classrooms Environment: A Holistic Approach," Int. J. I. Mob. Tech., vol. 11, pp. 39-56, 2017.

[8] World Economic Forum, "New Vision for Education: Fostering Social and Emotional Learning Through Technology," 2016.

[9] M. Al-Emran, K. Shaalan, "Learners and educators attitudes towards mobile learning in higher education: State of the art, in: Advances in Computing," Communications and Informatics, pp. 907-913, 2015.

[10] C. Newhouse, P. Williams, J. Pearson, "Supporting mobile education for pre-service professors. Australas," J. Educ. Technol., vol. 22, 2006.

[11] F. Ozdamli, "Pedagogical framework of m_learning," Procedia - Soc. Behav. Sci., vol. 31, pp. 927-931, 2012

[12] T. Miangah, A. Nezarat, "Mobile-assisted language learning," Int. J. Para. Syst., 3, 309, 2012.

[13] C. Valero, M. Redondo, A. Palacín, "Tendencias actuales en el uso de dispositivos móviles en educación," La Educ. Digit. Mag., vol. 147, pp. 1-21, 2012.

[14] E. Jackson, "M_learning Devices and their impact on Postgraduate Researchers Scope for improved Integration in the Research Community," Online J. New Horizons Educ., vol. 6, 2016.

[15] A. Biloš, D. Turkalj, I. Kelić, "Mobile Learning Usage and Preferences of Vocational Secondary School Students: The cases of Austria, the Czech Republic, and Germany," Naše Gospod. Econ., vol. 63, pp. 59-69, 2017.

[16] H. Chu, "Potential negative effects of mobile learning on students' learning achievement and cognitive load-a format assessment perspective," J. Ed. Tech. S., vol. 17, pp. 332-344, 2014.

[17] D. Solis, "Digital Transformation - The six stages of digital transformation", 2017.

[18] IDC, "Third platform," 2016, http://www.idc.com/promo/thirdplatform 
[19] F. Moreira, N. Durão, C.S. Pereira, M. J. Ferreira, "Mobile learning with gamification and augmented reality in Portuguese High Education," in: 9th International Conference on Education and New Learning Technologies (EDULEARN17). pp. 4263-4273, 2017.

[20] M. J. Goertzen, "Introduction to Quantitative Research and Data," Lib. Tech. Rep., vol. 53, pp. 1218, 2017.

[21] L.-V. Campenhoudt, R. Quivy, "Manual de Investigação em Ciências Sociais," G. Publicações, 2008.

[22] M.H. Pestana, J.N. Gageiro, "Análise de dados para Ciências Sociais. A complementaridade do SPSS," Edições Sílabo, 6a Edição, 2014.

[23] J. Maroco, "Análise Estatística com o SPSS," 6a edição, ReportNumber, Lda, 2014. 